\title{
Emotion Regulation and Attachment: Unpacking Two Constructs and Their Association
}

\author{
Sara F. Waters • Elita A. Virmani • Ross A. Thompson • \\ Sara Meyer $\cdot$ H. Abigail Raikes $\cdot$ Rachel Jochem
}

Published online: 23 September 2009

(C) The Author(s) 2009. This article is published with open access at Springerlink.com

\begin{abstract}
This study examined the association between the security of attachment and processes influencing the development of emotion regulation in young children. A sample of 734 1/2-year-olds and their mothers were observed in an emotion regulation probe involving mild frustration for children, and mothers and children were later independently interviewed about how the child had felt. Fewer than half the mothers agreed with children's selfreports in the emotion they attributed to children (a lower rate than the concordance of observer ratings with children's selfreports), and higher mother-child concordance was associated with secure attachment and mother's beliefs about the importance of attending to and accepting their own emotions. Mother-child conversations about recent events evoking children's negative emotion were also analyzed. Children were less likely to avoid conversing about negative feelings when they were in secure attachments and when mothers were more validating of the child's perspective. Children's greater understanding of negative emotions was also significantly associated with higher motherchild concordance and less child conversational avoidance. Taken together, these findings underscore the multiple influences of attachment on emotion regulation and the importance of children's emotion understanding to these processes.
\end{abstract}

Keywords Emotion regulation - Security of attachment . Sensitivity Emotion understanding

S. F. Waters $\cdot$ E. A. Virmani $\cdot$ R. A. Thompson $(\bowtie) \cdot S$. Meyer $\cdot$ H. A. Raikes $\cdot$ R. Jochem

Department of Psychology, University of California, Davis,

One Shields Ave.,

Davis, CA 95616, USA

e-mail: rathompson@ucdavis.edu
The security of attachment is associated with a variety of positive psychological outcomes for young children, including stronger peer relationships, enhanced selfconcept, greater emotion understanding, and better social problem-solving skills (see Thompson 2008, for a review). Emotion self-regulation is central to many of these psychological sequelae. Several studies have found that secure parent-child attachment is associated with inhibited toddlers' lower cortisol reactivity in challenging situations (Nachmias et al. 1996), more positive anger management strategies in preschoolers (Gilliom et al. 2002), and greater constructive coping with stress in middle childhood (Contreras et al. 2000).

These findings are consistent with theoretical views that the sensitive responsiveness of parents contributes to secure attachment and better emotion self-regulation through the adult's assistance when offspring are struggling to manage negative feelings (Cassidy 1994; Thompson 1994). Besides the parent's immediate responsiveness, however, there are other ways that parental behavior associated with a secure attachment may foster better emotion regulation in children. Parents in secure attachments may appraise children's feelings and their causes more accurately and insightfully, and thus provide more effective assistance. They may subsequently talk with the child about distressing experiences more thoughtfully and sensitively, and offer greater understanding of useful strategies for managing these feelings. In short, the characteristics associated with attachment security may foster emotion regulation in children in many ways.

The goal of this research study was to unpack the constructs of attachment and emotion regulation to examine how the security of attachment might be associated with processes influencing the development of emotion regulation in young children. First, we were interested in how 
attachment security was associated with mothers' attribution of emotion to their children in an emotion regulation task. Although accurately reading a child's feelings in a shared activity would appear easy and straightforward, we anticipated considerable variability in how much mothers' attributions of emotion were concordant with the child's own self-reports for reasons described below. Our central prediction was that mothers in secure relationships would subsequently describe the child's emotions in a manner more consistent with the child's own self-report, reflecting their greater sensitivity to the feelings of offspring. Second, we were interested in how attachment security was associated with the ease with which children would talk with their mothers about an upsetting event in light of the importance of such forums for maternal coaching about emotion regulation (Laible and Panfile 2009). Such conversations can be uncomfortable experiences for young children, but we expected that there would be less avoidance by children in secure relationships, owing in part to the mother's more accepting, validating conversational approach. We also included in this research other influences that might also affect maternal emotion attributions and child conversational avoidance, including the mother's own representations of emotion, depressive symptomatology, and the child's understanding of emotion.

\section{Attachment and Maternal Emotion Attributions}

Parents intervene both proactively and reactively to manage children's emotions with their coaching of self-regulatory strategies (Thompson and Meyer 2007). Central to these interventions, however, is the appropriateness of the adult's perception of the child's actual or anticipated feelings. A parent who is seeking to assist a young child in managing sadness will be helpful if the child is indeed experiencing sad affect, but will be less effective or relevant if the child instead is feeling anger, fear, or positive emotion.

The expectation that decoding a child's emotional experience should be a relatively straightforward prelude to offering support for emotion regulation may explain why little research has examined the accuracy of parental perceptions of young children's emotional experience. A study by Levine et al. (1999) suggests, however, why adult perceptions may often be different from those of children. Parents and their preschoolers were independently prompted to remember shared events in the recent past in which the child felt happiness, sadness, anger, or fear. These researchers found that the rate of agreement between the primary emotion reported by parent and child varied according to whether the emotion reported by the parent was happiness (.80), sadness (.72), fear (.49) or anger (.22). Subsequent analyses showed that disagreements often arose because parents and children had conflicting reports of the child's goals in the episode that led to their different emotion attributions. When the mother's emotional report was based on different assumptions concerning the child's goals in that situation, she more often disagreed with the child. In other circumstances, discordant perceptions of a child's feelings may derive from the parent's own emotional condition. A number of studies have found, for example, that depressed mothers respond to their children's emotions in ways reflecting their own preoccupation with sad affect, criticism, and helplessness which can distort their perceptions of the child's feelings (Goodman and Gotlib 1999).

Because the appropriate decoding of a young child's emotions is essential to parental attempts to support the emotion regulatory efforts of offspring, we examined the concordance of child and maternal perceptions of the child's feelings during an emotion regulation probe, and the origins of individual differences in mother-child agreement. The emotion regulation probe was a procedure in which the child received a candy or snack of his or her choice that the child was allowed to eat with the mother's permission, but mothers were independently instructed to delay the child from doing so until much later. Thus the subsequent interaction of mothers and children was focused on the mother's denial of the child's request and managing the child's ensuing negative feelings. Later, mothers and children were independently shown a videotape of their behavior during this procedure and asked how the child felt at this time, and why. Based on the findings of Levine and colleagues (1999), we anticipated that there would be some disagreements between maternal and child reports of the child's emotion during the denied request task, although we expected higher rates of agreement in this study because each was watching a videotape of a situation that had occurred a short time earlier, during which the child's goal was clear and explicit.

We also anticipated, however, that individual differences in the extent of mother-child agreement would be associated with the influence of four variables. The first was the security of mother-child attachment, based on the extensive research literature indicating the greater sensitivity of mothers of securely-attached children to the child's feelings and needs (De Wolff and van IJzendoorn 1997). The second was maternal depressive symptomatology, based on previous research suggesting distortions in perceptions of children's emotions by depressed mothers. Third, mothers' representations of emotion in their own lives - particularly their beliefs about the importance of attending to and accepting one's emotional experienceswas examined as a predictor of perceptions of emotion in children. This was based, in part, on the ideas of Gottman et al. (1997) that the "meta-emotion philosophy" by which parents contribute to children's emotion management is based on parents' own beliefs about emotion and its 
importance in their lives. Parents who value the influence of emotions in their own experience, for example, and believe that they merit acceptance are more likely to be attentive to the feelings of their children. This study is the first empirical test of this idea as it is associated with mothers' perception of their children's feelings. Fourth, we also considered child influences that might predict mother-child agreement concerning the child's emotional experience, and predicted that children with enhanced understanding of their own negative emotions are more likely to communicate and identify these feelings more clearly, and thus contribute to enhanced mother-child concordance.

\section{Attachment and Child Conversational Avoidance}

Parents also contribute to the development of emotion regulation when they later talk with children about recent experiences involving emotional arousal (Thompson and Meyer 2007). Retrospective reminiscing about events in the recent past has several advantages over immediate parental interventions in the socialization of emotion regulation. Young children are more likely to attend to and remember parents' coaching when they have emotional distance from the heightened arousal of the immediate situation. In addition, the conversational give-and-take between parent and child provides better opportunities to enhance children's developing knowledge about emotion regulation in the context of broader understanding of emotion, social rules concerning emotional displays, and the effects of these displays on others. A large research literature documents the importance of the content and quality of parent-child conversation on preschoolers' developing understanding of emotion (see Thompson 2006 for a review), and their developing knowledge of emotion regulation is influenced likewise (Laible and Panfile 2009). Parents talk more frequently with young children about negative than positive emotions and have more complex discourse with them about negative feelings, perhaps because negative emotions are more perplexing to young children and are more often the targets of regulatory efforts (Laguttuta and Wellman 2002).

As researchers who study parent-child conversations about negative emotional events have long recognized, however, young children often prefer not to discuss recent events that have been upsetting (see, e.g., Laible and Panfile 2009). They manifest this by changing the topic, evading the mother's queries, running away, or explicitly refusing to talk further. This is a natural response to maternal prompting to talk about uncomfortable or unsettling topics, but because conversations about negative emotional events also provide opportunities to talk about emotion regulation strategies, parents must adapt their conversational style to surmount child avoidance of this kind. Very little research has been devoted to understanding these parental tactics, however, despite their relevance to the impact of conversational quality on young children's understanding of negative emotion and its management.

This study is the first, therefore, to examine the predictors of young children's avoidance of negative emotion conversations with their mothers as a means of expanding understanding of how parent-child conversations influence the development of emotion understanding and emotion regulation. We were especially interested in three influences on the frequency of child evasion of this kind. The first was the security of attachment, with the expectation that children in secure relationships with their mothers would exhibit less avoidance than insecure children. This is consistent with theoretical claims that mothers and children in secure relationships have a more "open, fluid communication" that enables greater emotional sharing and discussion, particularly of negative emotions that might be more troubling, disturbing, or confusing to young children (Bretherton 1993). The second was maternal validation of the child's viewpoint during the conversation itself. This hypothesis was based on the expectation that mothers who are more validating would provide young children with a more comfortable and accepting interpersonal environment in which to discuss past experiences of sadness or anger. Finally, we examined whether child avoidance is also predicted by differences in children's understanding of negative emotions. Emotion understanding is likely to be significant to children's willingness to talk about their emotional experiences (children who have greater emotion knowledge are less likely to avoid the topic), and we focused on negative emotion understanding because of its more direct relevance to the conversational topic. We also examined the influence of maternal depressive symptomatology and emotion representations on child avoidance.

\section{Method}

\section{Participants}

A sample of 73 mothers and their 4 1/2-year-old children $(M=4.52$ years, $S D=.35 ; 45 \%$ female) participated in this study. They were recruited through child care and preschool programs in socioeconomically diverse communities. Ethnic diversity reflected the region in which the study was conducted: $57 \%$ of children were White, $19 \%$ were Latino, $4 \%$ were African American or Pacific Islander, and two or more ethnicities were indicated for $19 \%$ of the children. Educational background was similarly diverse: $28 \%$ of 
mothers had less than a college degree, $35 \%$ had completed college, and $35 \%$ had a master's or doctoral degree.

\section{Overview of Procedure}

Mothers and children participated in two laboratory sessions each lasting 1 to $11 / 2$ hours separated by a week. During the first session, mothers and children discussed together four emotionally salient events of the recent past: two events when the mother felt sad and angry and the child was present (excluding emergencies and when the child was the cause of the parent's emotions), and after several intervening assessments, they subsequently discussed two events when the child felt sad and angry (excluding disciplinary incidents and emergencies). Mothers nominated events from the past week in conversation with the experimenter outside of the child's hearing, and together they identified those that were consistent with the study criteria. Mothers were asked to discuss these experiences with their children as they normally would at home and to continue until they felt the conversation was naturally concluded. Mothers were prompted to help their children remember what happened, how they felt, and how they dealt with these emotions. Subsequently, the mother completed the Attachment Q-sort (Waters and Deane 1985), and children completed several assessments of emotion understanding.

During the second lab visit, mothers and children participated in the denied request task described below. Afterwards, mothers and children independently participated in separate interviews of what occurred during the denied request task and, in particular, the feelings of each during this emotion regulation probe. Mothers completed several measures, including the Trait Meta-Mood Scale (Salovey et al. 1995) and the Centers for Epidemiological Study of Depression inventory of depressive symptomatology (Radloff 1977), while children were being interviewed, and children played with an experimenter while their mothers were being interviewed. Mothers and children were reunited for another conversational task and clean up before departing. Children received a small gift for their participation.

\section{Measures}

Child avoidance The two mother-child conversations during the first lab visit that focused on events in the recent past when children felt sad and angry were analyzed for indications of child avoidance of the conversation topic. Digitized recordings of these conversations were coded by well-trained research assistants for verbal and behavioral indications of child avoidance, which consisted of words or actions in direct response to the mother's relevant question or statement.
Examples of child avoidance include (a) changing the topic (i.e., child actively tries to shift the conversational topic or focus of shared attention to something else), (b) explicit evasions or refusals (i.e., child verbally indicates refusal to continue the conversation in response to a maternal statement or question), and (c) behavioral evasions (e.g., in response to a maternal statement or question, child goes to the door and tries to leave, acts aggressively toward mother, or begins yelling loudly). Inter-rater reliability $(\mathrm{K}=.79)$ was based on an independent recoding of $25 \%$ of the records. In order to adjust for variable conversational duration, the frequency of child avoidance was divided by the total number of conversational turns, yielding proportion scores. The mean of child avoidance was $.13(S D=.18$, range $=.00$ to 1.26$)$.

Maternal validation Transcripts of these mother-child conversations were independently coded for the mother's validation of the child's viewpoint. Maternal validation was scored on a 5-point scale (5 indicating high validation) based on aspects of the mother's conversational contributions including (a) acceptance of the child's perspective about what happened even if it contradicts the mother's own view, (b) expressions of empathy for the child's feelings, and (c) placing the child's viewpoint, rather than the mother's, at the focus of the conversation. Inter-rater reliability $(\mathrm{K}=.78)$ was based on an independent recoding of $25 \%$ of the transcripts. The mean of maternal validation was $3.19(S D=1.08$, range $=1.00-5.00)$.

Security of attachment The Attachment Q-sort version 3.0 (AQS; Waters and Deane 1985), a commonly used measure of attachment for children age 1-5, was completed by mothers during the first lab visit. Mothers sorted 90 cards containing descriptive statements into nine groups based on how accurately each described their child. Each card in the Q-sort has been assigned a value reflecting the score a prototypically "most secure" child would receive on that item, and security scores were calculated by correlating the observed child's scores on the Q-sort items with the security criterion sort containing values for the prototypically secure child. Although some disagreement exists on whether mothers or trained observers provide the most valid information from the sort, the findings of Teti and McGourty (1996) suggest that because mothers have access to the most representative sample of their children's behavior, they are good candidates to perform the sort. To ensure the validity of their responses, however, mothers must be properly trained, kept blind to the construct being measured, sent the AQS items to look over in advance, and supervised during their sort in case questions arise. Such procedures have yielded predictive validity (consistent with attachment theory) in other studies (e.g., Laible and Thompson 1998; Teti and McGourty 1996; see van 
IJzendoorn et al. 2004), and thus were the procedures used in this study. The mean security score for this sample was $.37(S D=.18$, range -.08 to .68$)$, comparable to the mean of .32 for nonclinical samples reported by van IJzendoorn et al. (2004).

Child emotion understanding During the first lab visit, children participated in Denham's affective perspectivetaking task (Denham 1986), the primary measure of emotion understanding that has been used extensively in prior research. In the first part of the task, children's ability to recognize facial expressions associated with emotions was assessed. Children were presented with four felt puppet faces, one each with prototypically happy, sad, scared, and angry expressions, and for each face children were asked "How does this one feel?" Each child received two points for accurately naming the faces, and one point for the correct emotional valence but not the correct specific emotion (e.g., labeling an angry face as sad).

In the second part of the task, children were presented with 20 short vignettes, acted out by hand puppets whose gender matched the child's gender, describing an emotional event. The vignettes were accompanied by facial and vocal cues by the experimenter. In eight of the 20 stories, the puppet was shown to feel the same way that most people would feel in the given situation (e.g., happy to get ice cream); these were called the stereotypical vignettes. In the other 12 stories, the puppet was shown to feel opposite to how the child would feel, based on maternal reports of the child's typical feelings in these situations (e.g., happy vs. scared in the presence of a large friendly dog); these were called the nonstereotypical vignettes (mothers completed a questionnaire at the beginning of the visit that asked them to predict how their child would feel in each of the nonstereotypical stories). At the end of each story, children were asked "How does the puppet feel?" If children did not respond with a verbal emotion label, they were asked to point to the corresponding felt puppet face. Two points were given for an accurate response, and one point was given if children matched the valence of the emotion but did not accurately identify it.

Children's responses to the negative emotional expressions and the stories describing negative emotions were combined to create an index of negative emotional understanding. Because the number of stories describing negative emotion varied for children (based on maternal responses to the nonstereotypical vignettes), each child received a proportion score based on the total points divided by the total possible points for each part of the task (emotion labeling, stereotypical stories, and nonstereotypical stories). The resulting scores were converted into $z$ scores and then summed to create a score for negative emotion understanding. As standard scores were aggregated, the mean for this measure was $.00(S D=2.18$, range $=-7.82-2.27$ ).

Denied request task During the second lab visit, the child was allowed to choose a snack or candy as a reward from a variety of choices while the mother was out of the room. The experimenter told the child that it was $\mathrm{OK}$ to eat it immediately, but that first the child should consult with the mother after her return to the room. In another location, mothers were not informed of these instructions but were instead told by another experimenter that they should ensure that the child not eat the snack until after they had returned home from the lab visit. Mothers and children were then reunited. This "denied request task" has been shown in past research to induce moderate frustration in young children and has been used in studies of emotion regulation in preschoolers (Stansbury and Sigman 2000). Mothers and children were subsequently observed for 2 min, during which the experimenters who were filming the session jointly identified the peak of the child's emotional arousal and identified the time when this occurred on the clock counter superimposed on the videotape. At the end of $2 \mathrm{~min}$, the mother was given a prompt encouraging her to permit the child to eat the candy or snack immediately.

Mother and child emotion interview Later in the procedure, mothers and children were independently invited to a separate room where they were shown the videotape of the denied request task and interviewed about what happened, adapted from a procedure developed by Gottman and Levenson (1985) for studying marital interactions. The tape was played from the beginning of the procedure and stopped at the moment of the child's peak emotional intensity earlier identified. Children were asked to identify how they felt at this time by choosing one from a set of simple line drawings of facial expressions depicting happiness, anger, and sadness. (These emotions and their labels are within the emotion lexicon of children of this age and prior to viewing the videotape, children were prompted to provide the correct verbal label for each picture.) They also rated the intensity of that emotion using another picturecard representing increasing intensities of emotion through circles of increasing size that had been earlier introduced and explained. Children were also asked several other questions about why they felt as they did, what they could do to feel better, and how their mothers felt at this time and why. From the child's responses, the child's selfreported emotion attribution was identified (one child's response was lost due to a technical malfunction).

Subsequently, mothers watched the same video vignette and were also asked how the child felt and why, along with several other questions about behavior during the procedure. 
Mothers provided open-ended verbal responses to these questions, along with rating the intensity of each emotion they attributed to the child; mothers could attribute as many emotions to the child as they wished. Their emotion attributions to the child were subsequently coded into a smaller number of well-defined primary emotion categories based on the lexical emotion prototype research of Shaver and colleagues to establish their comparability to children's responses (see Shaver et al. 1987). The emotion categories into which maternal attributions of emotion were coded were: anger, sadness, happiness, fear, surprise, and neutral or indifferent. Two coders coded maternal emotion attributions of the child in this manner, establishing an interrater reliability of .93 . The mother's emotion attribution was scored as matching the child's self-report when any emotion the mother identified in the child matched the child's self-report, even if it was not the mothers's primary emotion attribution (i.e., the one she rated as greatest intensity).

Observational ratings of children's emotions To provide convergent evidence for the self-reports of the young children in this study, we conducted independent observational ratings of children's facial and verbal emotional expressions for the same episode in the videotape as when mothers and children were asked to describe the child's emotion. Based on prior studies of emotional expressiveness in young children (e.g., Izard 1991), research assistants were provided with behavioral markers of each of the emotion categories into which maternal emotion attributions were coded: anger (e.g., frown, scowl, lowered eyebrows, square mouth, harsh voice, stomping feet), sadness (e.g., pout, cry/sob, slumped posture, face in hands), happiness (e.g., clear smile, giggle/laugh, hugging), surprise (e.g., raised eyebrows, alert posture, "0" shaped mouth), fear (e.g., withdrawal, hesitation, self-protective posture, wide eyes, furrowed brow), and neutral / indifference (e.g., no distinguishing positive or negative affect). The videotapes of the denied request task episodes of 70 children were coded (three others were uncodeable) with an inter-rater reliability of .82 on a subsample of 20 videotapes.

Maternal depressive symptomatology The Center for Epidemiological Study of Depression inventory (CES-D; Radloff 1977) was used to assess the frequency of depressive symptoms experienced by mothers during the past 2 weeks (e.g., "I felt that everything I did was an effort"). Scores for depressive symptomatology are calculated by adding the number of days for which depressive symptoms were reported, with a potential range of scores of $0-60$ and scores of 16 or higher considered indicative of clinical depression. The mean score for this sample was
$10.66(S D=7.82$, range 0 to 37 , Cronbach's alpha $=.87)$. Twelve mothers in the sample were over the clinical cutoff of 16 .

Maternal attention to emotions The Trait Meta-Mood Scale (TMMS; Salovey et al. 1995) were used to assess mothers' attention to and acceptance of their own emotions. Parents used a 5-point Likert scale (5 indicating high agreement) to indicate how much they agreed with statements about emotions. The 13-item attention subscale was used to measure mothers' beliefs about the importance of attending to, and acceptance of, emotional experiences (e.g., "Feelings give direction to life"), yielding a summary mean score. For this sample, the mean score was $4.02(S D=.50$, range 3.00-5.00, Cronbach's alpha $=.79$ ).

\section{Results}

Associations Among Study Measures

The bivariate associations between the study measures are presented in Table 1. Security of attachment was significantly negatively associated with child avoidance, and positively associated with maternal validation, during the mother-child emotion conversations. Securely-attached children were less likely to avoid participating in the conversation, and their mothers used more validating comments. Child avoidance was also significantly negatively associated with maternal validation, and negatively correlated with child negative emotion understanding. The most avoidant children were lowest in their understanding of negative emotions, and their mothers were least validating in conversation. There were no other significant bivariate associations between the study variables.

\section{Children's Self-Reports and Observer Ratings of Emotion}

In their emotion interview, $25 \%$ of children reported that they felt primarily angry, $39 \%$ reported that they felt sad, and $36 \%$ reported that they felt happy in the denied request task. Not surprisingly, independent observers' ratings of children's emotional behavior in the task were consistent with children's self-reports. Observers rated $24 \%$ of children as primarily angry, $41 \%$ as sad, $24 \%$ as happy, and $10 \%$ as neutral or indifferent (no children were rated as primarily afraid or surprised). When the agreement between children's self-reports and observer reports is assessed as a direct match between them, there was a .54 rate of agreement in the primary emotion reported by children and observers (Goodman-Kruskal $\lambda=.36, p<.01$ ). Observational ratings were comparably consistent with children's 
Table 1 Bivariate associations among study measures

\begin{tabular}{|c|c|c|c|c|c|c|}
\hline & $\begin{array}{l}\text { Child } \\
\text { avoidance }\end{array}$ & $\begin{array}{l}\text { Maternal } \\
\text { validation }\end{array}$ & $\begin{array}{l}\text { Security } \\
\text { of } \\
\text { attachment }\end{array}$ & $\begin{array}{l}\text { Neg. Emo. } \\
\text { Understand. }\end{array}$ & $\begin{array}{l}\text { Maternal } \\
\text { depression }\end{array}$ & $\begin{array}{l}\text { Attention } \\
\text { to } \\
\text { emotion }\end{array}$ \\
\hline Child avoidance & - & $-.31 * *$ & $-.30 * *$ & $-.41 * *$ & .02 & .03 \\
\hline Maternal validation & & - & $.24 *$ & .10 & .04 & .11 \\
\hline Security of attachment & & & - & .10 & -.07 & -.03 \\
\hline $\begin{array}{l}\text { Negative emotion } \\
\text { understanding }\end{array}$ & & & & - & .06 & .06 \\
\hline Maternal depression & & & & & - & -.20 \\
\hline $\begin{array}{l}\text { Attention to emotion } \\
\text { (TMMS) }\end{array}$ & & & & & & - \\
\hline
\end{tabular}

$* p<.05 * * p<.01$

Predictors of Individual Differences in Mother-Child Concordance

Point-biserial correlations between the index of motherchild concordance and the remaining study variables yielded significant relations with security of attachment ( $\mathrm{r}$ $(73)=.29, p<.05)$ and children's understanding of negative emotions $(r(73)=.25, p<.05)$. A logistic regression analysis was conducted to examine the predictors of mother-child agreement on the emotion shown by the child in the denied request task. The predictor variables were the security of attachment, child negative emotion understanding, maternal depressive symptomatology, and the measure of maternal attention to emotions. In the first step, child negative emotion understanding was found to be a significant predictor of mother-child concordance: mothers were more likely to report emotions consistent with the child's report when children were stronger in comprehending their own feelings. In the second step, with differences in child emotion understanding controlled, the remaining variables were included. The results indicated that attachment security and the mother's attention to emotion were each significant predictors of whether mothers provided emotion attributions that were consistent with children's self-reports (Table 3). Child negative emotion understanding remained a marginal predictor of mother-child concordance. Mothers who believed in the importance of attending to and accepting their own emotional experiences, and who were in a more secure attachment relationship with their children, were more likely to perceive emotion in their children that was consistent with children's self-reports.

\section{Predictors of Individual Differences in Child Avoidance}

Hierarchical linear regression analyses examined the prediction of child avoidance from the hypothesized influences of security of attachment, maternal validation, and child negative emotion understanding (Table 4). Child negative emotion understanding was again entered first, and was a significant predictor. Children with better understanding of negative agreement. 
Table 2 Concordance between maternal attributions of emotion and child self-reports

\begin{tabular}{|c|c|c|c|c|c|c|c|c|}
\hline & & \multicolumn{7}{|c|}{ Maternal attributions of emotion to the child } \\
\hline & & Angry & Sad & Happy & Afraid & Surprised & Neutral & Total \\
\hline \multirow[t]{4}{*}{ Child self-reports } & Angry & 5 & 4 & 3 & 4 & 0 & 2 & 18 \\
\hline & Sad & 6 & 13 & 5 & 1 & 0 & 3 & 28 \\
\hline & Happy & 1 & 5 & 11 & 2 & 1 & 6 & 26 \\
\hline & Total & 12 & 22 & 19 & 7 & 1 & 11 & 72 \\
\hline
\end{tabular}

emotions were less likely to avoid conversation with their mothers about recent sad or angry experiences. In the second step, security of attachment and maternal validation were also found to significantly predict child avoidance, while child negative emotion understanding remained a significant predictor. Children were less likely to avoid conversation about negative emotions when they were in secure attachment relationships, and when mothers conversed in a manner that was validating and accepting of the child's viewpoint.

Prior research indicates that the security of attachment interacts with maternal conversational quality in predicting young children's emotion understanding and other outcomes, suggesting that the broader quality of the parent-child relationship is important to the influence of conversational style (Laible and Thompson 2000). Consequently, in the third step of the regression analysis, the interaction of security and validation was entered. The interaction term was significant, although attachment security was no longer a significant direct predictor of child avoidance. To understand the nature of this interaction further, the association between child avoidance and parent validation was graphed at one standard deviation above the mean, one standard deviation below the mean, and at the mean of scores for attachment security (Fig. 1). The figure indicates that the association between conversational validation and child avoidance was strongest for young children in the most insecure relationships with their mothers; this association was also apparent for children at the mean of attachment security. In each case, the slopes of the association between validation and avoidance were significant. By contrast, for children in the most secure attachment relationships, there was essentially no association between parent validation and child avoidance.

\section{Discussion}

The goal of this research was to conceptually unpack the constructs of emotion regulation and attachment to understand their association more incisively. Security of attachment was unpacked to examine the multiple manifestations of maternal sensitivity that contribute to security and foster emotion regulation in offspring. Emotion regulation was unpacked to examine the constituent processes in mother-child relationships that guide the development of emotion regulation in the early years. By focusing on mothers' attribution of emotion to children in an emotion regulation probe, and their support in conversations about negative emotional experiences during which regulation strategies can be discussed, the findings of this study elucidate several ways that these constructs are related.

\section{Maternal Emotion Attributions in Emotion Regulation}

The results of this study suggest the difficulty in what is often assumed to be a relatively straightforward task in parental coaching of emotion regulation: sensitively discerning the child's emotional response. In an interview in which they watched a videotape of the denied request task that had occurred earlier in the lab session, fewer than half the mothers of this study attributed emotion to the child that matched children's self-reports. Their rate of agreement was substantially lower than that reported by Levine et al. (1999), even though the target event had occurred earlier in the session, mothers and children reviewed a videotape of the event, and there was considerably less ambiguity concerning the child's goals than in the situations sampled in the Levine study. Mothers' agreement with their children
Table 3 Predicting motherchild concordance

$+p<.10 * p<.05 * * p<.01$

\begin{tabular}{llllll}
\hline Variable & \multicolumn{2}{l}{ Step 1 } & & & \multicolumn{2}{l}{ Step 2 } \\
\cline { 2 - 3 } \cline { 5 - 6 } & Odds ratio & $95 \%$ CI & & Odds ratio & $95 \%$ CI \\
\hline Emotion understanding (negative emotions) & $1.31^{*}$ & $1.01-1.71$ & & $1.28+$ & $0.97-1.70$ \\
Attention to emotion & & & $3.53^{*}$ & $1.05-11.86$ \\
Maternal depression & & & 1.04 & $0.96-1.12$ \\
Security of attachment & & & $90.53^{*}$ & $2.51-3262.30$ \\
& $\chi^{2}(1)=4.88^{*}$ & & $\chi^{2}(4)=15.93^{* *}$ \\
\hline
\end{tabular}


Table 4 Predicting child avoidance in mother-child conversations about negative emotion

\begin{tabular}{|c|c|c|c|c|c|c|c|c|c|}
\hline \multirow[t]{2}{*}{ Variable } & \multicolumn{3}{|c|}{ Step 1} & \multicolumn{3}{|c|}{ Step 2} & \multicolumn{3}{|c|}{ Step 3} \\
\hline & $B$ & $S E B$ & $\beta$ & $B$ & $S E B$ & $\beta$ & $B$ & $S E B$ & $\beta$ \\
\hline $\begin{array}{l}\text { Emotion } \\
\text { understanding } \\
\text { (negative } \\
\text { emotions) }\end{array}$ & -.03 & .01 & $-.41^{* *}$ & -.03 & .01 & $-.37 * *$ & -.03 & .01 & $-.37 * *$ \\
\hline $\begin{array}{l}\text { Security of } \\
\text { attachment }\end{array}$ & & & & -.21 & .11 & $-.21 *$ & -.18 & .11 & -.17 \\
\hline Maternal validation & & & & -.04 & .01 & $-.23 *$ & -.04 & .02 & $-.23 *$ \\
\hline $\begin{array}{l}\text { Attachment } \mathrm{x} \\
\text { Validation }\end{array}$ & & & & & & & .21 & .10 & $.21^{*}$ \\
\hline $\mathrm{R}^{2}$ & & .17 & & & .29 & & & .33 & \\
\hline$F$ for change in $R^{2}$ & & $14.57 * *$ & & & $5.60 * *$ & & & $4.40 *$ & \\
\hline
\end{tabular}

was also significantly lower than that of observers who rated the child's behavior during the videotape excerpt but had not been present during the denied request task and were unfamiliar with the child.

The sensitivity of parental attributions of emotion to young children is important to their coaching of emotion regulation. If adults misconstrue a child's feelings in the immediate context or when retrospectively reminiscing with the child, it can potentially contribute to young children's mislabeling of their emotional experience, blending of the adult's emotional attribution with their own, or confusion about what they truly felt (Denham et al. 2007). With respect to emotion regulation, the concordance of the

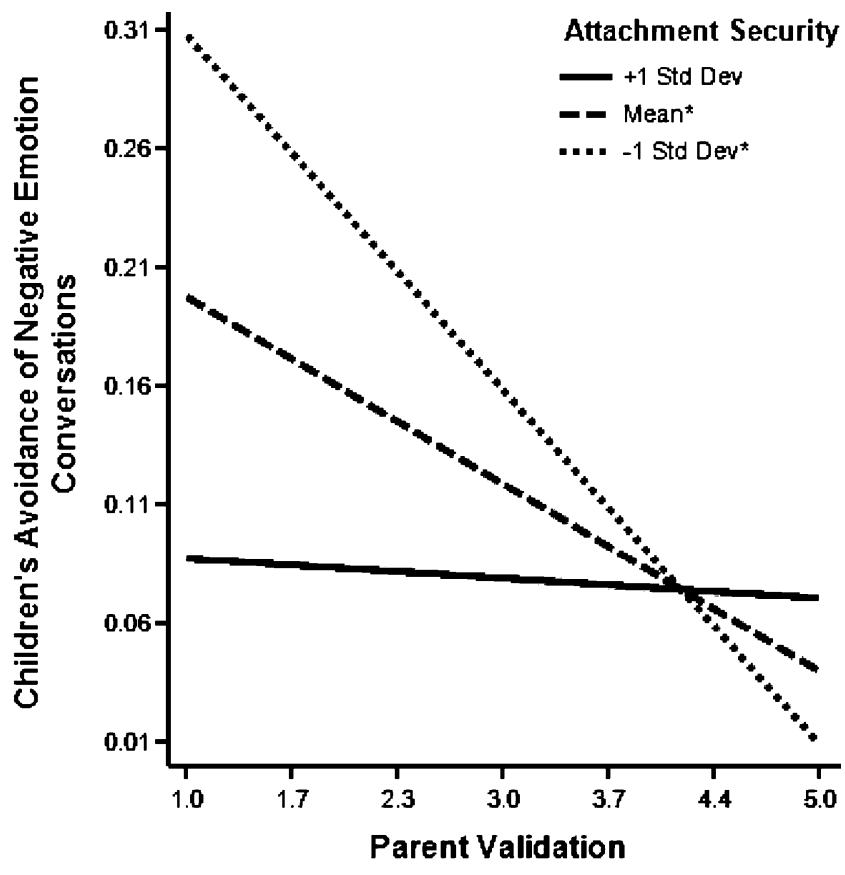

* Slope significant at $p<.05$

Fig. 1 Interaction of attachment and parent validation in predicting children's avoidance of negative emotion conversations adult's attributions of emotion to the child is important because many strategies for emotion management are emotion-specific (e.g., managing anger by changing or redirecting goals; regulating sadness by eliciting sympathetic support; managing fear by leaving the situation). If a parent perceives a child as angry when the child is instead sad or happy, it is likely to result in inappropriate or irrelevant emotion coaching by the adult. Thus it appears that parents face a greater challenge than is often assumed in supporting the development of competent skills of emotion regulation in young children because of the difficulty of accurately interpreting the child's feelings in the immediate situation. For parents and children facing more complex emotional challenges than the denied request task, or when children have emotional difficulties (such as anxious or depressive psychopathology), this may be particularly challenging.

The agreement between observers' behavioral ratings of children's emotions and children's self-reports, especially in light of the difficulties of coding facial and vocal emotional expressions in freely-mobile young children, suggests that in most cases young children were reporting their emotional experience in a manner consistent with their earlier behavior. Nevertheless, the discrepancies between welltrained observers and children's self-reports of specific emotions are also instructive. They may arise because (a) young children are providing unclear emotional signals of their feelings in the immediate situation and/or (b) young children do not always report the same emotion in the subsequent interview that they experienced in the task. In this regard, the finding that children with better understanding of negative emotions were more concordant with their mothers' reports suggests that children's understanding and awareness of their feelings (coupled with the ability to communicate their emotions clearly) may be an important contribution to mother-child agreement. Moreover, children and adults may disagree also because they focus on different aspects of the emotion regulation 
situation. For example, children who reported feeling happy even though reliable observers rated them as sad may have reported on the basis of the satisfaction they felt at the conclusion of the task (when they could eat the desired treat), even though the video interview emphasized feelings when the treat was denied.

These findings also identify other reasons for disagreements between maternal attributions and children's selfreports. The mothers in this study agreed least when their children reported feeling angry, consistent with the results of Levine and colleagues (1999). Because mother was the source of the child's frustration in the denied request task, the potential hostility of an angry child may have caused mothers to attribute different feelings (including fear) to the child instead. In addition, the agreement of the mother's attributions with the child was also predicted by the mother's representations of emotion in her personal life. Mothers who believed that emotions are important, worthy of attention, and provide valid guidance seem to have extended this belief to the attention they devoted to their children's feelings, at least as it was reflected in the concordance of their perceptions of the child's emotions with the child's own. This confirms the importance of understanding the characteristics of the perceiver in emotional understanding, and compels attention to the parents' representations of emotion in their own lives in studies of emotion regulation in children.

Finally, the security of attachment was also an important predictor of the concordance of maternal perceptions and child self-report, consistent with the well-replicated association of parental sensitivity with secure attachment (see De Wolff and van IJzendoorn 1997). Mothers in more secure relationships with their children were more likely to attribute the same emotions to their children as children did to themselves.

\section{Child Avoidance in Conversations about Negative Emotion and its Regulation}

Because parent-child conversation is a significant catalyst to developing understanding of emotion and emotion regulation, this study also examined conversational factors that can ease children's willingness to converse about prior experiences of negative emotion, which are often contexts for discussions of emotion regulation. The findings from this study indicate that children are least likely to avoid conversations about negative emotions when their mothers validate and accept the child's viewpoint, when there is a secure attachment relationship, and when children possess strong prior understanding of negative emotions.

Consistent with the research literature on autonomy support in parent-child relationships (e.g., Deci and Ryan 2002), the mother's accepting, child-centered approach provides young children with relational support in conversing about personal challenges, a contribution similar to that offered by a secure attachment to the parent. Indeed, secure attachment and maternal validation were significantly correlated. In this study, consistent with expectations, a secure attachment was a significant direct predictor of lower child avoidance in conversations about negative emotion. This conclusion is consistent with the arguments of attachment theorists that secure dyads enjoy more open, responsive shared communication, especially about difficult topics (Bretherton 1993). Moreover, maternal validation was especially influential in the context of insecure attachments. For children who experienced the greatest insecurity with their mothers, or who were at the mean of attachment security, the negative association between maternal validation and child avoidance was strong and significant — but this was not true for children who obtained the highest security scores. These findings suggest that when young children lack the support afforded by attachment security, mothers who converse in a validating manner provide needed affirmation in the immediate context and, in so doing, reduce the likelihood of child avoidance.

Finally, the results indicate that child avoidance was also predicted by children's understanding of negative emotions. These findings suggest (awaiting the confirmation of future research) that children who have already achieved competence in understanding negative, distressing feelings are more comfortable engaging in conversation about them and, in so doing, are likely to further expand their knowledge.

\section{Concluding Comments}

The findings of this study underscore not only the significance of attachment for emotion regulation but also the unique importance of children's emotion understanding, especially of negative feelings. Children with greater comprehension of negative emotion were less likely to avoid conversation with their mothers about previous upsetting experiences-even with the influences of attachment and maternal conversational validation controlled. Likewise, children with enhanced understanding of negative emotion were more concordant with their mothers in how they described their feelings in the emotion regulation probe with other influences on mother-child agreement controlled. In each case, emotion understanding contributed unique variance to predicting constructive relational processes associated with the growth of emotion regulation. Children who have greater comprehension of their feelings appear to be more competent at understanding, communicating, and conversing about those feelings with adults who can contribute further to their knowledge of and capacities for managing those emotions. This is especially true of the 
negative, distressing feelings that are most perplexing to children and elicit greatest regulatory effort by children and their parents.

Acknowledgements We are very grateful for the assistance of Abby Winer in this research.

Open Access This article is distributed under the terms of the Creative Commons Attribution Noncommercial License which permits any noncommercial use, distribution, and reproduction in any medium, provided the original author(s) and source are credited.

\section{References}

Bretherton, I. (1993). From dialogue to internal working models: The co-construction of self in relationships. In C. A. Nelson (Ed.), Memory and affect in development. Minnesota Symposia on Child Psychology, Vol. 26 (pp. 237-263). Hillsdale: Erlbaum.

Cassidy, J. (1994). Emotion regulation: Influences of attachment relationships. In N. A. Fox (Ed.), The development of emotion regulation and dysregulation: Biological and behavioral aspects. Monographs of the Society for Research in Child Development, 59 (2-3), 228-249 (Serial no. 240).

Contreras, J. M., Kerns, K. A., Weimer, B. L., Gentzler, A. L., \& Tomich, P. L. (2000). Emotion regulation as a mediator of associations between mother-child attachment and peer relationships in middle childhood. Journal of Family Psychology, 14, 111-124.

Deci, E. L., \& Ryan, R. M. (eds). (2002). Handbook of selfdetermination research. Rochester: University of Rochester Press.

Denham, S. (1986). Social cognition, pro-social behavior, and emotion in preschoolers: contextual validation. Child Development, 57, 194-201.

Denham, S., Bassett, H. H., \& Wyatt, T. (2007). The socialization of emotional competence. In J. Grusec \& P. Hastings (Eds.), Handbook of socialization (pp. 614-637). New York: Guilford.

De Wolff, M. S., \& van IJzendoorn, M. H. (1997). Sensitivity and attachment: a meta-analysis on parental antecedents of infant attachment. Child Development, 68, 571-591.

Gilliom, M., Shaw, D. S., Beck, J. E., Schonberg, M. A., \& Lukon, J. L. (2002). Anger regulation in disadvantaged preschool boys: strategies, antecedents, and the development of self-control. Developmental Psychology, 38, 222-235.

Goodman, S. H., \& Gotlib, I. H. (1999). Risk for psychopathology in the children of depressed mothers: a developmental model for understanding mechanisms of transmission. Psychological Review, 106, 458-490.

Gottman, J. M., \& Levenson, R. W. (1985). A valid procedure for obtaining self-report of affect in marital interaction. Journal of Consulting and Clinical Psychology, 53, 151-160.

Gottman, J. M., Katz, L. F., \& Hooven, C. (1997). Meta-emotion: How families communicate emotionally. Mahwah: Erlbaum.

Izard, C. E. (1991). The psychology of emotions. New York: Plenum.

Laible, D., \& Thompson, R. A. (1998). Attachment and emotional understanding in preschool children. Developmental Psychology, 34, 1038-1045.

Laible, D., \& Thompson, R. A. (2000). Mother-child discourse, attachment security, shared positive affect, and early conscience development. Child Development, 71, 1424-1440.
Laible, D., \& Panfile, T. (2009). Mother-child reminiscing in the context of secure attachment relationships: Lessons in understanding and coping with negative emotions. In J. Quas \& R. Fivush (Eds.), Stress and memory development: Biological, social and emotional considerations. Oxford Series in Affective Science (pp. 166-195). New York: Oxford University Press.

Laguttuta, K., \& Wellman, H. (2002). Differences in early parent-child conversations about negative versus positive emotions: Implications for the development of psychological understanding. Developmental Psychology, 38, 564-580.

Levine, L., Stein, N., \& Liwag, M. (1999). Remembering children's emotions: sources of concordant and discordant accounts between parents and children. Developmental Psychology, 35, $790-801$.

Nachmias, M., Gunnar, M., Mangelsdorf, S., Parritz, R. H., \& Buss, K. (1996). Behavioral inhibition and stress reactivity: the moderating role of attachment security. Child Development, 67, $508-522$.

Radloff, L. S. (1977). The CES-D Scale: a self-report depression scale for research in the general population. Applied Psychological Measurement, 1, 385-401.

Salovey, P., Mayer, J. D., Goldman, S. L., Turvey, C., \& Palfai, T. P. (1995). Emotional attention, clarity, and repair: Exploring emotional intelligence using the Trait Meta-Mood Scale. In J. Pennebaker (Ed.), Emotion, disclosure, \& health (pp. 125-154). Washington: American Psychological Association.

Shaver, P., Schwartz, J., Kirson, D., \& O'Connor, C. (1987). Emotion knowledge: further exploration of a prototype approach. Journal of Personality and Social Psychology, 52, 1061-1086.

Stansbury, K., \& Sigman, M. (2000). Responses of preschoolers in two frustrating episodes: emergence of complex strategies for emotion regulation. Journal of Genetic Psychology, 161, 182-202.

Teti, D., \& McGourty, S. (1996). Using mothers vs. trained observers in assessing children's secure base behavior: theoretical and methodological considerations. Child Development, 67, 597-605.

Thompson, R. A. (1994). Emotion regulation: A theme in search of definition. In N. Fox (Ed.), The development of emotion regulation and dysregulation: Biological and behavioral aspects. Monographs of the Society for Research in Child Development, 59 (serial no. 240), 25-52.

Thompson, R. A. (2006). The development of the person: Social understanding, relationships, self, conscience. In W. Damon \& R. M. Lerner (Eds.), Handbook of child psychology (6th Ed.), Vol. 3. Social, emotional, and personality development (N. Eisenberg, Vol. Ed.) (pp. 24-98). New York: Wiley.

Thompson, R. A. (2008). Early attachment and later development: familiar questions, new answers. In J. Cassidy \& P. R. Shaver (Eds.), Handbook of attachment (2nd ed.). New York: Guilford.

Thompson, R. A., \& Meyer, S. (2007). The socialization of emotion regulation in the family. In J. Gross (Ed.), Handbook of emotion regulation (pp. 249-268). New York: Guilford.

van IJzendoorn, M. H., Vereijken, C. M. J. L., BakermansKranenburg, M. J., \& Riksen-Walraven, J. M. (2004). Assessing attachment security with the Attachment $Q$-Sort: meta-analytic evidence for the validity of the observer AQS. Child Development, 75, 1188-1213.

Waters, E., \& Deane, K. (1985). Defining and assessing individual differences in attachment relationships: Q-methodology and the organization of behavior in infancy and early childhood. In I. Bretherton \& E. Waters (Eds.), Growing points of attachment theory and research. Monographs of the Society for Research in Child Development, 50 (Serial no. 209), 41-65. 